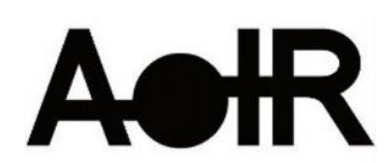

Selected Papers of \#AoIR2021:

The 22nd Annual Conference of the

Association of Internet Researchers

Virtual Event / 13-16 Oct 2021

\title{
RECOMMENDED FOR YOU: INVESTIGATING THE USE OF ALGORITHMIC NEWS RECOMMENDATION IN THE SCANDINAVIAN DAILY PRESS
}

\author{
Lynge Asbjørn Møller \\ Aarhus University
}

A growing number of news websites have adopted algorithmic news recommender systems to automatically structure and order news items using logical statements and information on user preferences (Möller et al., 2018). While these systems provide news organisations with new opportunities to offer more relevant and even personalised news experiences and in turn keep and grow traffic, their increasing use has also raised several concerns about whether and how algorithms should undertake important editorial decisions. The commercial origin of these technologies has prompted critical questions about the influence of commercial considerations on news production (Bodó, 2019), while discussions on personalised news recommendation point to traditional debates on journalism's role in the fragmentation of the public sphere (Milosavljević \& Vobič, 2019). Traditional news media organisations thus have to navigate a complex landscape when implementing algorithmic news recommender systems.

However, current literature offers only limited empirical insight into the actual use of algorithmic news recommender systems in journalism. A dominating strand of inquiry into the field has focuses on normative considerations about the potentials and limitations of news recommendation (Helberger, 2015, 2019; Helberger et al., 2018), while empirical research has examined the effect of different recommender systems (Möller et al., 2018), explored the user attitudes (Bodó et al., 2019; Monzer et al., 2020) and news media perspectives (Bastian et al., 2020; Bodó, 2019) toward the technologies and mapped their use in journalism at early stages of the emerging practice (Thurman, 2011; Thurman \& Schifferes, 2012). This study addresses the above-mentioned gap in the literature by mapping the adaptation of news recommendation within the Scandinavian daily press and gathering qualitative data on the professional attitudes towards these technologies. This geographical focus balances US-centric literature with insights from a media system with different legal rules, cultural policies and journalistic traditions. The paper addresses the following questions: 
- How has the Scandinavian daily press implemented algorithmic news recommendation?

- What are the reasonings behind choosing to implement or not implement these technologies?

- Which concerns were central in this decision-making process, and how were these concerns addressed?

\section{Methods}

The paper draws on interviews with all 19 national newspapers within the Danish, Norwegian and Swedish daily press. With the exception of one email exchange, semistructured interviews were conducted with representatives at all the newspapers between December 2020 and January 2021, determining whether each newspaper uses algorithmic news recommendation, whether the systems are personalised, whether the systems are developed in-house, where on the website news recommendation is in place, and which kind of filtering is applied. Furthermore, the research interviews were used to investigate the reasonings behind implementing the technology and central concerns in the decision-making process, thus bringing a qualitative dimension to the analysis and allowing for a perspective on how journalists at different news organisations evaluate the use of algorithmic news recommendation and its further potential.

\section{Findings}

The study finds that news recommender systems are adopted by 17 out of the 19 newspapers studied, with personalisation implemented at 14 of these. While the extent of their use at the specific newspapers is for the most part still in an experimental phase, attitudes towards news recommendation were generally positive. The reasonings for their implementation include among other things increasing the relevance of the user experience, unlocking the long tail of content, driving subscriptions, and freeing up journalists time from routine tasks. The findings also highlight several concerns with the implementation of algorithmic news recommendation.

A significant cause for concern was losing editorial control. Especially newspapers relying on ad-based online business models emphasised their humanly edited front page as too important for the business to be automated. This constraint seemingly relates to how many commercial news organisations develop their brands based on what Becker and Vlad (2009, p. 66) call a 'news philosophy' that, according to Thurman (2011, p. 399), 'shapes the type and mix of stories covered'. The few reluctant newspapers in this study may see algorithmic news recommendation as reducing their control over their brand, thus negatively affecting their commercial success.

A majority of the newspapers also expressed concern that the algorithms would interfere with journalistic priorities, create filter bubbles and amplify only popular content, leading to users missing out on important news stories. These concerns led over one third of the newspapers to implement specific precautionary measures to counteract these negative effects, such as protecting top stories or creating safe pools of articles for the recommender to promote. Furthermore, a quarter of the recommender systems mapped in this study were designed to allow for editorial input on news items' 
importance in terms of public interest, enabling the systems to provide each individual user with the most important news stories that they might have missed.

The findings of this study thus show that journalistic norms and ideals affect the design and implementation of algorithms in journalism, indicating that it is not unlikely that the use of algorithmic news recommendation will become more accepted as a sound practice in journalism. But these findings are based on interviews with employees responsible for implementation of these technologies and may not represent the sentiments of the newsroom as a whole, necessitating further endeavours that expand the scope of interviewees to include newsroom staff. Such research may illuminate potential journalistic tensions within the newsroom and explore whether or not algorithmic curation is actually accepted by journalists and why.

\section{References}

Bastian, M., Makhortykh, M., Harambam, J., \& van Drunen, M. (2020). Explanations of news personalisation across countries and media types. Internet Policy Review, 9(4). https://doi.org/10.14763/2020.4.1504

Becker, L. B., \& Vlad, T. (2009). News Organizations and Routines. In K. WahlJorgensen \& T. Hanitzsch, The Handbook of Journalism Studies (pp. 59-72). Routledge.

Bodó, B. (2019). Selling News to Audiences - A Qualitative Inquiry into the Emerging Logics of Algorithmic News Personalization in European Quality News Media. Digital Journalism, 7(8), 1054-1075. https://doi.org/10.1080/21670811.2019.1624185

Bodó, B., Helberger, N., Eskens, S., \& Möller, J. (2019). Interested in Diversity. Digital Journalism, 7(2), 206-229. https://doi.org/10.1080/21670811.2018.1521292

Helberger, N. (2015). Merely facilitating or actively stimulating diverse media choices? Public service media at the crossroad. International Journal of Communication, 9(1), 1324-1340.

Helberger, N. (2019). On the Democratic Role of News Recommenders. Digital Journalism, 7(8), 993-1012. https://doi.org/10.1080/21670811.2019.1623700

Helberger, N., Karppinen, K., \& D’Acunto, L. (2018). Exposure diversity as a design principle for recommender systems. Information, Communication \& Society, 21(2), 191-207. https://doi.org/10.1080/1369118X.2016.1271900

Milosavljević, M., \& Vobič, I. (2019). Human Still in the Loop. Digital Journalism, 7(8), 1098-1116. https://doi.org/10.1080/21670811.2019.1601576

Möller, J., Trilling, D., Helberger, N., \& Es, B. van. (2018). Do not blame it on the algorithm: An empirical assessment of multiple recommender systems and their impact on content diversity. Information, Communication \& Society, 21(7), 959977. https://doi.org/10.1080/1369118X.2018.1444076 
Monzer, C., Moeller, J., Helberger, N., \& Eskens, S. (2020). User Perspectives on the News Personalisation Process: Agency, Trust and Utility as Building Blocks.

Digital Journalism, 8(9), 1142-1162.

https://doi.org/10.1080/21670811.2020.1773291

Thurman, N. (2011). Making 'The Daily Me': Technology, economics and habit in the mainstream assimilation of personalized news. Journalism, 12(4), 395-415. https://doi.org/10.1177/1464884910388228

Thurman, N., \& Schifferes, S. (2012). The Future of Personalization at News Websites. Journalism Studies, 13(5-6), 775-790.

https://doi.org/10.1080/1461670X.2012.664341 